\title{
ESTABLISHING NORMATIVE VALUE OF MITRAL VALVE THICKNESS DETERMINED BY 2D ECHOCARDIOGRAPHY IN 3000 NORMAL CHILDREN AGED 5-15 YEARS OF MANIPUR, A NORTH-EASTERN INDIAN STATE
}

Rajendra Singh Thangjam ${ }^{1}$, Rameshchandra ${ }^{2}$, Rothangpuii ${ }^{3}$, I. Anil ${ }^{4}$, Anita Saxena ${ }^{5}$, Ramakrishnan ${ }^{6}$

\section{HOW TO CITE THIS ARTICLE:}

Rajendra Singh Thangjam, Rameshchandra, Rothangpuii, I. Anil, Anita Saxena, Ramakrishnan. "Establishing Normative Value of Mitral Valve Thickness Determined by 2D Echocardiography in 3000 Normal Children Aged 5-15 Years of Manipur, A North-Eastern Indian State". Journal of Evolution of Medical and Dental Sciences 2015; Vol. 4, Issue 45, June 04; Page: 7767-7776, DOI: 10.14260/jemds/2015/1130

ABSTRACT: INTRODUCTION: Recent studies giving importance to subclinical Rheumatic Heart Disease (RHD) diagnosed by echocardiography have led to variable results of disease burden depending on the different criteria of diagnosis used, which include thickened mitral valve (MV) as one component. Data regarding normal thickness of MV estimated by echocardiography is extremely limited. Most studies of RHD detection are based on autopsy studies measuring MV thickness. Hence, we felt establishing normative value of MV thickness in our population is essential. MATERIAL \& METHODS: A cross sectional echocardiographic study was carried out among 3386 randomly selected school children, aged 5-15 years $(11.18 \pm 2.83,47.23 \%$ female), living in the rural and urban areas of Manipur to study the average thickness of Mitral valve. RESULTS: In 3000 normal children selected out of the total 3386 individuals screened, for whom data is complete, analysis shows the average mean thickness of MV as $2.47 \mathrm{~mm} \pm 0.39$ SD. Subgroup analysis shows MV thickness of $2.30 \mathrm{~m}$ $\pm 0.37,2.49 \mathrm{~mm} \pm 0.38,2.65 \mathrm{~mm} \pm 0.38$ in individuals with $\mathrm{BMI}<16,16-20,>20$ respectively; $2.22 \mathrm{~mm} \pm$ $0.32,2.40 \mathrm{~mm} \pm 0.34,2.47 \mathrm{~mm} \pm 0.40$ in children with SBP $<90 \mathrm{mmHg}, 90-100 \mathrm{mmHg},>100 \mathrm{mmHg}$ respectively. CONCLUSIONS: The average mean thickness of mitral valve determined by 2D echocardiography in children of $5-15$ yrs. is $2.47 \pm 0.39 \mathrm{~mm}$ (Range $1.3-5.3 \mathrm{~mm}$ ). The thickness is more in older age group and in individuals with higher BMI and blood pressure.

KEYWORDS: Normal thickness of mitral valve by 2D echo, Subclinical RHD.

INTRODUCTION: In poor and developing nations rheumatic heart disease remains a major cause of morbidity and premature death and imposes a substantial burden on health care systems with limited budgets. ${ }^{(1,2)}$ Nevertheless, primary and secondary prevention efforts may be highly effective.(1) Secondary prevention relies on accurate case detection for the appropriate use of prophylactic antibiotics and regular medical surveillance. Exact prevalence data are also highly desirable to facilitate health care planning.

Various reports published on echocardiographic screening for RHD have used different sets of criteria.(3-5) It seems that a combination of Doppler and morphological criteria would be most ideal and will avoid overestimation. However, in regions with a high burden of RHD, these criteria may be too strict and may miss some cases.

Valvular thickening has been demonstrated to be a feature of RHD on echocardiography.(6-11) Available data does not clearly define the quantum of thickness of mitral valve to be characteristic of RHD. Most of the older research report depended on the subjective impression of the echocardiographer. The recent World Heart Federation (WHF) 2012 criteria.(12) define thickened MV as more than $3 \mathrm{~mm}$ in children. 
As there has been no work from this subcontinent to define the normal thickness of the MV in children, we felt it is pertinent to conduct such study to avoid any underestimation of subclinical RHD using higher cut off point of mitral valve thickness.

It is also generally agreed that valve thickness is overestimated to some extent by keeping THI on in the machine. But measuring the thickness of valve using both technique of THI off and on is time consuming and we felt the difference is not gross enough to affect in decision making if we are extra careful to avoid overestimation.

METHODOLOGY: This is a cross-sectional epidemiological survey study conducted during a period about 2 years commencing from June 2012 in Manipur, which represent an underdeveloped region of the world. Manipur is situated in the eastern corner of India and has a unique geographical characteristic of having a blend of valley and larger portion of hilly areas covering a total area of $22,327 \mathrm{sq} . \mathrm{km}$. hosting a population of $27,21,756$ inhabitants.

50 schools in the 9 districts of the state were randomly selected and identified to study the prevalence of subclinical RHD. The Principals of these schools were initially approached with a consent form, explaining the project details and the procedure to be adopted. Once the Principal agreed for carrying out the study, self-explanatory consent forms for parents were distributed to children aged 5-15 years through their class teacher. The project team visited the schools for the study after consent forms had been collected.

The trained paramedical staff noted the demographic data as per Performa. The onsite physician/investigator took a brief history including that suggestive of rheumatic fever and examine the child. The examination includes general physical examination inclusive of recording height, weight, waist circumference to measure body mass index. The blood pressure (BP) was measured for every child. We used aneroid Sphygmomanometer (Diamond) using proper sized cuff. In case the first reading was higher than $90^{\text {th }}$ centile for age, gender and height (Systolic/Diastolic or both), a second and third reading was taken after the child had rested for 10 minutes or more.

Cardiovascular examination was performed for any respiratory distress, cyanosis, cardiomegaly, congestive heart failure, abnormal heart sounds, murmurs etc. first by any one of the post graduate degree holder physician and immediately reexamined by a cardiologist, if necessary, in case of doubt. Clinical data were recorded in the Performa. Thereafter, an echocardiography including color Doppler was performed, using a portable echo machine (Sonosite M turbo) for all children in the study by a single cardiologist.

As we wanted to look into the difference in the thickness of MV by echocardiography with and without tissue harmonic imaging (THI), we recorded the images by the 2 technique in 112 randomly selected subjects. In the rest of the subjects measurement was recorded keeping the THI on as we felt the difference by the 2 technique is marginal ranging from 0.10 to $0.30 \mathrm{~mm}$. However, during the process of our study we recheck the thickness keeping THI off in all the individuals in whom the MV appears thickened.

The thickness of MV was recorded at the thickest point in the fully opened AML with the chordae separated from it and its axis plane more or less perpendicular to the plane of the MV ring. Utmost care has been taken to make sure that the AML is not over swung and the measurement is done in corresponding points as regards the position of the AML and distance of the point from the tip of the valve while still considering the thickest point. All the echocardiographic images are stored in digital format for later review by 2 other investigators (Cardiologists). 
If any abnormality were detected, necessary counseling and advice for further management were given to the parents subsequently.

STATISTICAL ANALYSIS: Descriptive statistics such as mean, standard deviation for continuous data and percentages for categorical data were used to describe the data of the study. Kolmogrov-Smirnov test and Shapiro-Wilk test were used to see the normal distribution of the data. For continuous data Kruskal Wallis $\mathrm{H}$ test was used to describe the differences between groups. If the $\mathrm{p}$ value $<0.05$, each group was compared using Mann Whitney U test as post hog test with Bonferroni correction. For paired continuous data, Wilcoxon Signed Ranked test was used.

RESULTS: A total of 3386 children have been screened over the last 2 years. Out of total 3386 children screened during this period, 3000 normal children for whom the data was complete were selected for the analysis of MV thickness. The mean age was 11.6 \pm 2.86 (Range being 5-15 years). The base line characteristics are given in table I.

\begin{tabular}{|c|c|c|c|}
\hline Characteristics & Range & Mean & Standard Deviation \\
\hline Age (years) & 5 to 15 & 11.6 & 2.86 \\
\hline Class & 1 to 10 & 5.25 & 2.78 \\
\hline Males/ females & $1758 / 1628$ & & 2.12 \\
\hline Number of Family members & $2-24$ & 6.05 & 1.76 \\
\hline Number of rooms & $1-15$ & 3.59 & 12.07 \\
\hline Weight (Kg.) & $10-83$ & 34.38 & 16.52 \\
\hline Height (cm) & $86.9-179.5$ & 136.44 & 8.12 \\
\hline $\begin{array}{c}\text { Waist circumference (cm) } \\
\text { 2423 students }\end{array}$ & $27-97$ & 60.2 & 3.76 \\
\hline BMI & $10.95-29.98$ & 17.80 & 12.34 \\
\hline Systolic BP & $61-167$ & 110.14 & 9.61 \\
\hline Diastolic BP & $29-108$ & 70.58 & \\
\hline Table I: Baseline Characteristics of 3386 Children Enrolled \\
\hline
\end{tabular}


The proportion of the children at different ages (5-15 years) is given separately for boys and girls in table II.

\begin{tabular}{|c|c|c|c|c|c|c|}
\hline \multirow{2}{*}{ Age (years) } & \multicolumn{2}{|c|}{ Male } & \multicolumn{2}{c|}{ Female } & \multicolumn{2}{c|}{ Total } \\
\cline { 2 - 7 } & No. & $\mathbf{\%}$ & No. & $\mathbf{\%}$ & No. & \% \\
\hline 5 & 60 & $1.77 \%$ & 57 & $1.68 \%$ & 117 & $3.45 \%$ \\
\hline 6 & 87 & $2.56 \%$ & 79 & $2.33 \%$ & 166 & $4.90 \%$ \\
\hline 7 & 116 & $3.42 \%$ & 109 & $3.21 \%$ & 225 & $6.64 \%$ \\
\hline 8 & 100 & $2.95 \%$ & 123 & $3.63 \%$ & 223 & $6.58 \%$ \\
\hline 9 & 123 & $3.63 \%$ & 137 & $4.04 \%$ & 260 & $7.67 \%$ \\
\hline 10 & 171 & $5.05 \%$ & 195 & $5.75 \%$ & 366 & $10.80 \%$ \\
\hline 11 & 173 & $5.10 \%$ & 137 & $4.04 \%$ & 310 & $9.15 \%$ \\
\hline 12 & 218 & $6.43 \%$ & 205 & $6.05 \%$ & 423 & $12.49 \%$ \\
\hline 13 & 274 & $8.09 \%$ & 214 & $6.32 \%$ & 488 & $14.41 \%$ \\
\hline 14 & 217 & $6.40 \%$ & 206 & $6.08 \%$ & 423 & $12.49 \%$ \\
\hline 15 & 219 & $6.46 \%$ & 166 & $4.90 \%$ & 385 & $11.37 \%$ \\
\hline Total & 1758 & $51.91 \%$ & 1628 & $48.09 \%$ & 3386 & $100 \%$ \\
\hline
\end{tabular}

Table II: Age and Gender Distribution of Study Population

For analysis, the subjects were categorized into different groups of age 5-7, 8-12, 13-15 years; BMI less than 16, 16-20, more than 20; SBP less than 90, 90-99, more than $100 \mathrm{mmHg}$. The average mean thickness of AML in normal children is $2.40 \mathrm{~mm}$.

The difference in the thickness of MV according to differing age, BMI and SBP is depicted in Table III-V respectively as given below.

\begin{tabular}{|c|c|c|c|}
\hline Age & No. of children & Mean $\mathbf{\pm}$ SD $\mathbf{( m m )}$ & Range $\mathbf{( m m )}$ \\
\hline 5 to 7 years & 332 & $2.21 \pm 0.39$ & $1.3-4.0$ \\
\hline 8 to 12 years & 1431 & $2.39 \pm 0.35$ & $1.4-3.6$ \\
\hline 13 to 15 years & 1237 & $2.64 \pm 0.38$ & $1.6-5.3$ \\
\hline
\end{tabular}

Table III: Description of MV thickness in different age groups

\begin{tabular}{|c|c|c|c|}
\hline BMI & No. of children & Mean \pm SD $(\mathbf{m m})$ & Range $(\mathbf{m m})$ \\
\hline Below 16 & 880 & $2.31 \pm 0.3$ & $1.3-4.0$ \\
\hline 16 to 24 & 1494 & $2.49 \pm 0.38$ & $1.5-5.3$ \\
\hline Above 20 & 626 & $2.65 \pm 0.38$ & $1.5-4.4$ \\
\hline
\end{tabular}

Table IV: Description of MV thickness in different groups of BMI

\begin{tabular}{|c|c|c|c|}
\hline Systolic BP & No. of children & Mean $\mathbf{\pm}$ SD (mm) & Range (mm) \\
\hline Below 90 & 26 & $2.22692 \pm 0.32$ & $1.7-2.8$ \\
\hline 90 to 99 & 189 & $2.40476 \pm 0.34$ & $1.5-3.3$ \\
\hline Above 100 & 2428 & $2.47879 \pm 0.40$ & $1.3-5.3$ \\
\hline
\end{tabular}

Table V: Description of MV thickness in different groups of Systolic BP 
In children with clinical or subclinical RHD (3 children in our study 1 clinical and 2 Subclinical by WHF 2012 criteria), the average mean thickness of AML was $3.26 \mathrm{~mm}$. In another 14 children who have trivial Mitral valvular regurgitation (Seen in 2 orthogonal planes but short of WHF criteria of significant lesion), the average mean thickness of the valve was $3.1+0.72 \mathrm{~mm}$. We also noticed very few individual who apparently has significantly thickened AML yet no Doppler effect of valvular regurgitation thereby debarring them from the diagnosis of Subclinical RHD.

Among the subgroups of different age, BMI and BP significant difference was found in the thickness of the mitral valve. The difference was statistically significant more in the groups of older vs younger age and higher vs lower BMI $(\mathrm{p}<0.001)$ than in the group of higher vs lower BP $(\mathrm{p}=0.003)$.

In a selective 112 subjects, in whom the measurement of the valve thickness was done using with and without Tissue Harmonic Imaging technique, a difference in the thickness was noticed in the range of $0.10-0.30 \mathrm{~mm}$ and this difference was found to be significant as noticed by Kolmogorov-Smirnov ( $\mathrm{p}=0.005)$ and post-hog analysis using Wilcoxon Signed Rank test $(\mathrm{p}=0.001)$.

The effect of THI on the thickness of valve and the importance of the proper selection of the site of measurement and the valve position are depicted in Fig. 1-3. The image in Fig. 4 shows the picture of a minimally thickened MV but deformed with characteristics of RHD while the image in Fig. 5 shows apparently normal looking valve morphology but having significant mitral regurgitation.

DISCUSSION: The modified World Health Organization (WHO) criteria, ${ }^{[5]}$ define RHD using echocardiography including fulfilling Doppler criteria (A regurgitate jet of $>1 \mathrm{~cm}$ in length, regurgitate jet in at least 2 planes, a mosaic color jet with a peak velocity of $>2.5 \mathrm{~m} / \mathrm{s}$, and jet persisting throughout systole or diastole) associated with at least 2 morphologic signs including leaflet restriction, subvalvular thickening, and valve leaflet thickening. However this criterion does not mention the cut off value of AML thickness to define thickened MV. The most recently adopted WHF 2012 criteria defines thickened MV as having thickness of more than $3 \mathrm{~mm}$ in children below 20 years of age.

In our study which was ultimately aimed at detection of subclinical RHD, we found many cases of significant looking mitral regurgitation yet no obvious thickening $(<3 \mathrm{~mm})$ but some degree of irregularity in the margin or minor deformity. So if we go by the strict criteria of WHF 2012 such cases will miss their detection and recognition. On the other hand, some cases who were already confirmed to have acute rheumatic fever about 3 months ago, happened to get reexamined in the study by the same investigator, and found them to have trivial mitral regurgitation with completely normalized morphological features of MV. Ultimately more cases of subclinical RHD who would benefit from prophylactic penicillin would remain undetected if they happened to get examined at one point of time only.

There seems to be some uncertainty regarding the normal thickness of the mitral valve. Some investigator has reported the thickness of mitral valve as less than $5 \mathrm{~mm} .{ }^{(13,14)}$ The thickness of MV was studied by Sahasakul in one of the best designed study in 200 individuals. The mean thickness at each site was not different between men and women but increased significantly with age (P less than 0.001). For 3 age groups (Less than 20, 20 to 59 and greater than or equal to 60 years), the corresponding mean thicknesses $(\mathrm{mm})$ of the aortic nodule were $0.67,0.87$ and 1.42; those for the anterior mitral leaflet were $1.30,1.60$ and 3.20.(15) Normal valve thickness was shown to be agerelated by Sahasakul et al. in a well-designed postmortem study (level 2++ evidence), and correlation 
between surgical and echocardiographic measurements seems to be good if harmonic imaging is not used, as this modality increases apparent tissue thickness.(10,15-19)

On the basis of data from a study of 280 healthy children in New Zealand.(20) the normal echocardiographic thickness of the anterior MV leaflet (AMVL) in school-aged children is 1.12-2.92 $\mathrm{mm}$ (mean \pm SD of $2.02 \pm 2 \mathrm{~mm}$ ) (level $2++$ evidence). Two smaller pediatric studies also support the concept that normal valve thickness is $<3 \mathrm{~mm}$ (level $2+$ evidence).

Our finding in the thickness of MV in normal children is at par with other previous echocardiographic study mentioned above, and slightly higher value compared to Sahasakul's postmortem anatomical study.(15) The difference in our finding is that the valve thickness appears to be more in individuals with higher BMI and higher SBP compared to the respective lower groups.

As we hypothesized before, the difference in the thickness value of MV resulting from using two different techniques does not affect the decision making thereby meaning that in no case the thickened MV defined by THI was negated by non-THI method. In other words, we could define thickened MV characteristic of RHD using THI in all cases. The limitation is that the direct comparison between THI and non-THI has been conducted in only 112 individuals.

CONCLUSION: This study is intended to look into the normal thickness of mitral valve in subjects dwelling in this part of the country. From this study we find that there is no influence of racial or geographical factor in the thickness of the MV. The average mean thickness of mitral valve determined by 2D echocardiography in children of $5-15$ yrs. is $2.47 \pm 0.39 \mathrm{~mm}$ (range $1.3-5.3 \mathrm{~mm}$ ). The thickness is more in older age group and in individuals with higher BMI and blood pressure. We also found that the value determined by THI method exceeds that of non-THI by a definite but marginal value ranging from $0.10-0.30 \mathrm{~mm}$. We also conclude that one can depend on the 2D echocardiographic THI picture routinely for the morphological characteristics of RHD and non-THI may be needed only in selective cases.

ACKNOWLEDGMENT: We express our deep and sincere thanks to Miss Priscila Kayina, Assistant Professor of Statistics from the department of Preventive and Social Medicine who has helped us all in the statistical analysis process of the study. Sincere thanks also go to all the paramedical and nursing staffs that helped us all throughout the study in the field work.

\section{REFERENCES:}

1. Anon. Rheumatic fever and rheumatic heart disease. World Health Organ Tech Rep Ser 2004; 923: $1 \mathrm{e} 122$.

2. Carapetis JR. Rheumatic heart disease in developing countries. N Engl J Med 2007; 357: 439e41.

3. Carapetis JR, Hardy M, Fakakovikaetau T, et al. Evaluation of a screening protocol using auscultation and portable echocardiography to detect asymptomatic rheumatic heart disease in Tongan schoolchildren. Nat Clin Pract Cardiovasc Med2008; 5: 411e17.

4. Marijon E, Celermajer DS, Tafflet $M$, et al. Rheumatic heart disease screening by echocardiography: the inadequacy of World Health Organization criteria for optimizing the diagnosis of subclinical disease. Circulation 2009; 120: 663e8.

5. Rheumatic fever and rheumatic heart disease. World Health Organ Tech Rep Ser 2004; 923: 1122. 
6. Vasan, R.S.et al. Echocardiographic evaluation of patients with acute rheumatic fever and rheumatic carditis.Circulation1996; 94: 73-82.

7. Yuko-Jowi, C. \& Bakari, M. Echocardiographic patterns of juvenile rheumatic heart disease at the Kenyatta National Hospital, Nairobi. East Afr.Med.J.2005; 82: 514-519.

8. Lembo, N.J.et al. Mitral valve prolapse in patients with prior rheumatic fever.Circulation.1988; 77: 830-836.

9. Atalay, S., Ucar, T., Ozcelik, N, Ekici, F. \& Tutar, E. Echocardiographic evaluation of mitral valve in patients with pure rheumatic mitral regurgitation.Turk.J.Pediatr.2007; 49: 148-153.

10. Vijayalakshmi, I. B., Vishnuprabhu, R.O., Chitra, N., Rajasri, R. \& Anuradha, T V. The efficacy of echocardiographic criterions for the diagnosis of carditis in acute rheumatic fever. Cardiol. Young 2008; 18: 586-592.

11. Camara, E. J., Neubauer, C., Camara, G. F. \& Lopes, A. A. Mechanisms of mitral valvar insufficiency in children and adolescents with severe rheumatic heart disease: an echocardiographic study with clinical and epidemiological correlations. Cardiol. Young 2004; 14: 527-532.

12. Remenyi B et. al. WHF criteria for echocardiographic diagnosis of rheumatic heart disease- an evidence-based guideline. Nat. Rev. Cardiol. Advance online publication 28 February 2012; doi: 10.1038/nrcardio.2012.7.

13. Silbiger JJ, Bazaz R. Contemporary insights into the functional anatomy of the mitral valve. American Heart Journal.2009; 158: 887-895.

14. Ho SY. Anatomy of the mitral valve.Heart.2002; 88 Suppl 4: iv5-10.

15. Sahasakul, Y., Edwards, W.D., Naessens, J. M. \& Tajik, A. J. Age-related changes in aortic and mitral valve thickness: implications for two-dimensional echocardiography based on an autopsy study of 200 normal human hearts. Am. J. Cardiol.1988; 62: 424-430.

16. Gorgulu, S.et al. Influence of different echocardiographic imaging modes on the assessment of anterior mitral leaflet thickness. J. Heart Valve Dis.2005; 14: 204-208.

17. Hirata, K.et al. Pitfalls of echocardiographic measurement in tissue harmonic imaging: in vitro and in vivo study. J. Am. Soc.Echocardiogr.2002; 15: 1038-1044.

18. Prior, D.L.et al. Impact of tissue harmonic imaging on the assessment of rheumatic mitral stenosis.Am.J.Cardiol.2000; 86: 573-576.

19. Hawkins, K., Henry, J. S. \& Krasuski, R. A. Tissue harmonic imaging in echocardiography: better valve imaging, but at what cost? Echocardiography 2008; 25: 119-123.

20. Webb, R., Lean, F., Zeng, I.\& Wilson, N. Objective measurement of mitral valve thickness with and without rheumatic heart disease [Abstract].5th World congress of paediatric cardiology and cardiac surgery [online], http://www.pccs2009.com/abstract/825.asp (2009). 


\section{ORIGINAL ARTICLE}

Fig. 1: Showing Overestimation of MV thickness by $0.30 \mathrm{~mm}$ using THI technique.

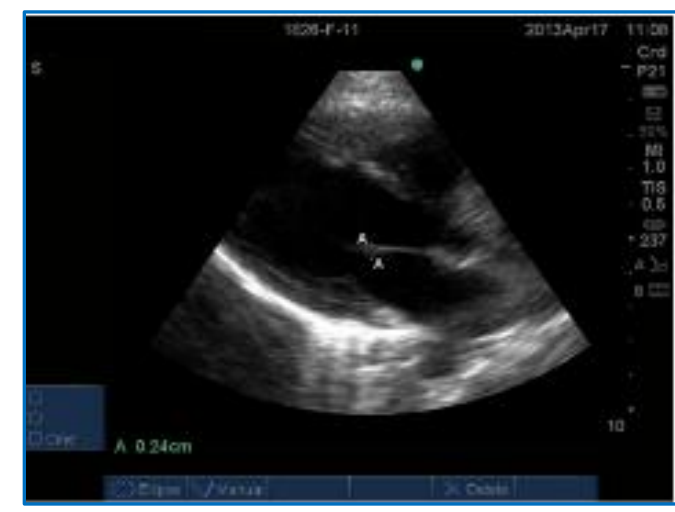

1A: 2D Echocardiogram with THI off

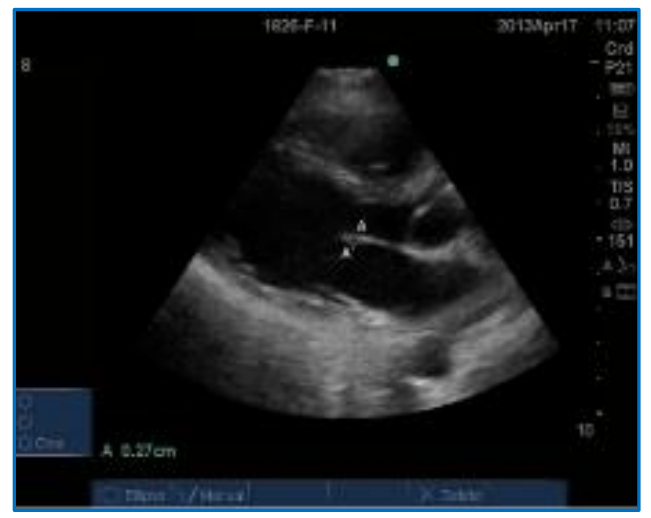

1B: 2D Echocardiogram with THI on

Fig. 2: Showing underestimation of MV thickness by THI implying the importance of position of the valve rather than the THI technique off or on.

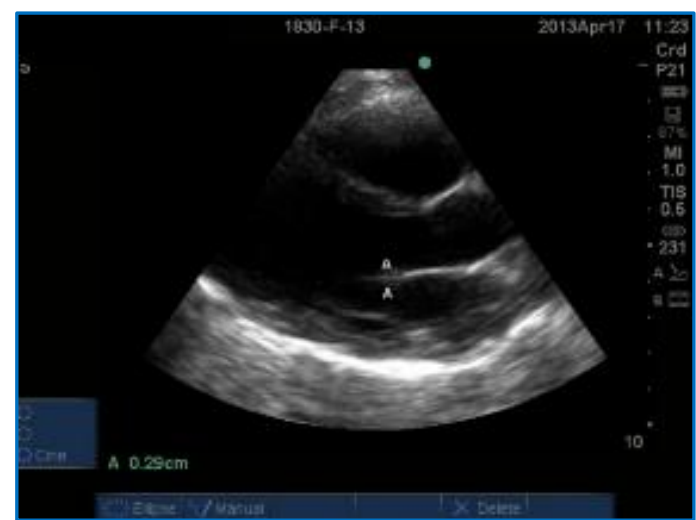

2A: 2D Echocardiogram with THI off

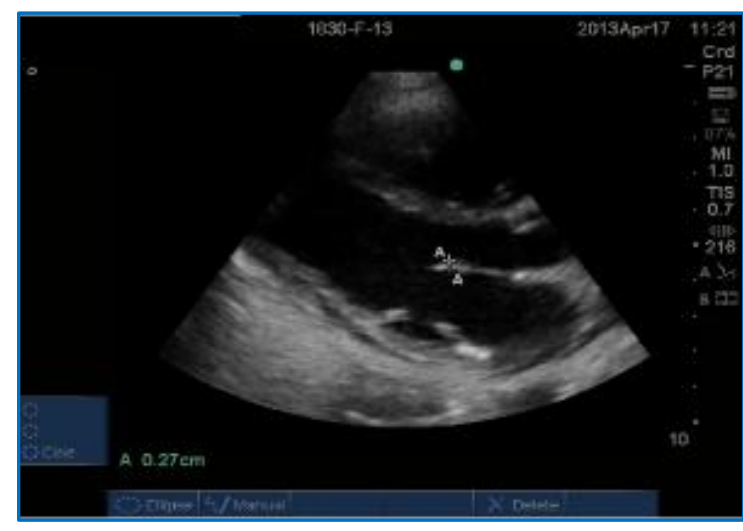

2B: 2D Echocardiogram with THI on

Fig. 3: Showing similar thickness of MV with or without THI provided the position of the valve is proper and measurement is accurate.

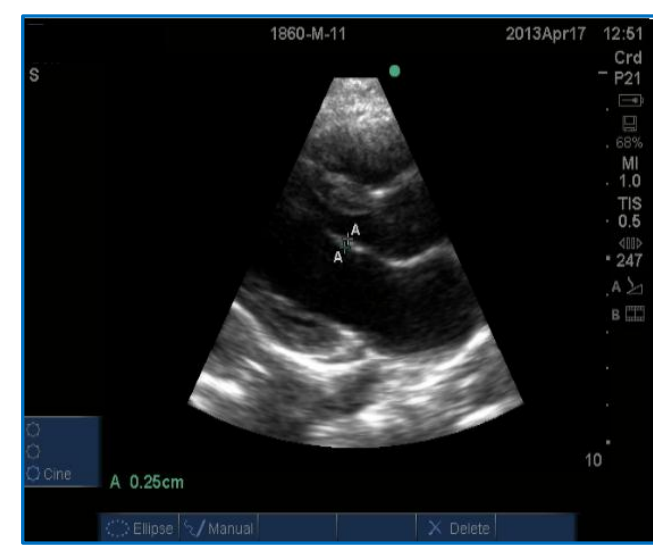

3A: 2D Echocardiogram with THI on

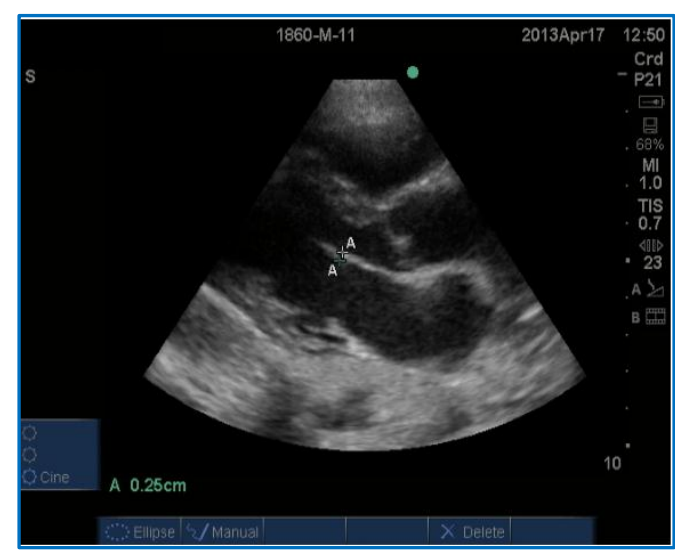

3B: 2D Echocardiogram with THI on 


\section{ORIGINAL ARTICLE}

Fig. 4: THI 2D echo picture showing minimally thickened MV tip with hockey stick deformity characteristic of RHD.

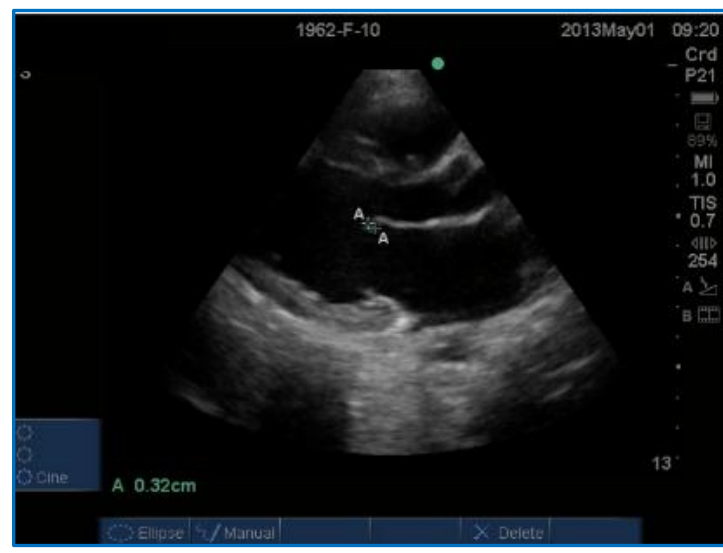

Fig. 4

Fig. 5: Showing apparently normal or non-thickened MV with significant Mitral regurgitation.

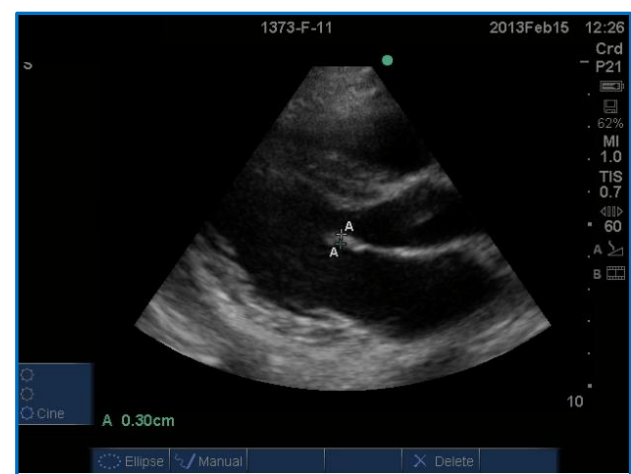

5A: PLAX view showing MV thickness

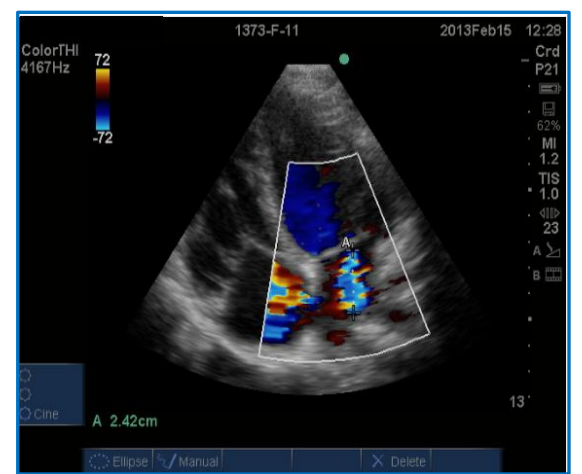

5C: Apical 4C view showing MR jet

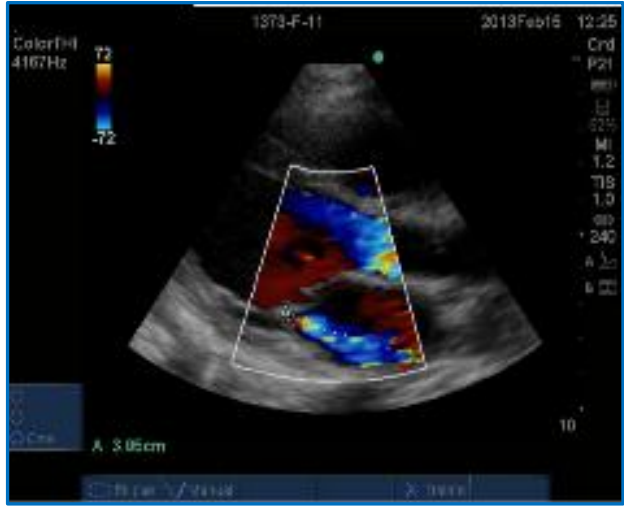

5B: PLAX view showing MR jet

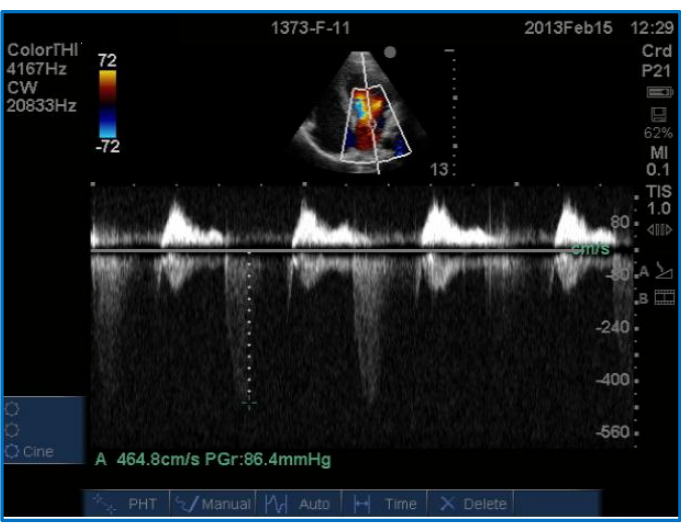

5D: Color Doppler showing nearly Holosystolic MR jet 


\section{ORIGINAL ARTICLE}

\section{AUTHORS:}

1. Rajendra Singh Thangjam

2. Rameshchandra

3. Rothangpuii

4. I. Anil

5. Anita Saxena

6. Ramakrishnan

\section{PARTICULARS OF CONTRIBUTORS:}

1. Assistant Professor, Department of Medicine, Jawaharlal Nehru Institute of Medical Sciences, Imphal.

2. Senior Resident, Department of Medicine, Jawaharlal Nehru Institute of Medical Sciences, Imphal.

3. Assistant Professor, Department of Medicine, Jawaharlal Nehru Institute of Medical Sciences, Imphal.

\section{FINANCIAL OR OTHER} COMPETING INTERESTS: None
4. Assistant Professor, Department of Medicine, Jawaharlal Nehru Institute of Medical Sciences, Imphal.

5. Professor, Department of Cardiology, AIIMS, Delhi.

6. Additional Professor, Department of Cardiology, AIIMS, Delhi.

\section{NAME ADDRESS EMAIL ID OF THE} CORRESPONDING AUTHOR:

Dr. Rajendra Singh Thangjam,

Department of Medicine, JNIMS, Imphal (Porompat), Manipur.

E-mail: rajdr2002@yahoo.co.in

Date of Submission: 26/05/2015. Date of Peer Review: 27/05/2015. Date of Acceptance: 29/05/2015. Date of Publishing: 02/06/2015. 